\title{
Research on Educational Management of Academic Postgraduate Students
}

\author{
Shaojun Zhang ${ }^{1, a}$, Mingyu Wang ${ }^{1, b *}$, Xin Peng ${ }^{1, c}$, Jiagan $\mathrm{Li}^{1, \mathrm{~d}}$ and Fulin $\mathrm{Yu}^{1, \mathrm{e}}$ \\ ${ }^{1}$ College of Naval architecture and Marine Engineering, Shandong Jiaotong University, 1508 \\ Hexing Road, 264310, Weihai, China \\ asjzhangwh@163.com, bvicsee@163.com, ${ }^{\mathrm{c} 289828684 @ q q . c o m,{ }^{\mathrm{d}} 40490455 @ q q . c o m,}{ }^{\mathrm{e}}$ \\ ufulin1988@qq.com \\ * The Corresponding Author
}

\section{Keywords: Postgraduate student; Quality control; Systematic construction}

\begin{abstract}
This research attempts to apply the basic concept and principle of ISO9000 quality management system in the training of academic postgraduates. In view of the existing problems, we should establish a scientific, rigorous and effective internal quality assurance system for academic postgraduates, so as to meet the needs of postgraduate education development and guarantee the healthy development of academic postgraduate education. Through the construction of the system, the idea of teaching is changed from "emphasizing the result" to "process control", which provides a reference sample for postgraduate education management and quality pursuit.
\end{abstract}

\section{Introduction}

Postgraduate education for academic postgraduates is mainly based on training teaching and research talents [1]. It focuses on theoretical education, with university teachers and research institutes as the main objectives. The classification and cultivation of graduate students require academic and professional, each with special emphasis. However, in the process of training, employment orientation and conditions restrict many training institutions to consciously or unconsciously blurred the boundary between academic and professional in training methods and training objectives, which affected the cultivation effect of core competitiveness of postgraduates. Academic postgraduate is the main force of sentific research, and it is an important reserve force for the construction of innovative country. In order to cultivate more innovative academic talents with original ability, we must re-examine and reflect on the training mode and effect of academic postgraduate in China over the past 30 years, find problems, improve work and enhance the innovative ability of academic postgraduates. All academic graduate students have diplomas and diplomas, so the society has a higher degree of recognition for such graduates [2]. The education and training of postgraduates not only shoulder the heavy responsibility of transporting applied talents for enterprises and governments, but also confronted with the needs of disciplinary research and development talents for discipline construction, which makes the training objectives of graduate students show diverse trends $[3,4]$. In the era of knowledge economy, to cultivate a large number of graduate education in the teaching and research staff at universities and research institutions, may value orientation and change the training of graduate students, to cultivate pioneering spirit, innovative technology and application of high level talents as its main goal[5,6]. With the expansion of postgraduate education, the expanded part should focus on training talents and emerging talents in this field, forming a new pattern for training postgraduates with application oriented as the main body $[7,8]$.

\section{The Present Situation of Postgraduate Management}

The Prominent Problems. In recent years, our country has continuously expanded the enrollment scale of graduate students to meet the national needs for high-level talents. In the past 2000-2014 years, the enrollment scale of China's postgraduates has increased year by year, which makes the ability of higher education resources to be almost limited, which leads to a downward trend in educational quality of 
academic postgraduates. In the course of training, the problems of the quality of the academic postgraduate education are mainly in the following aspects:

The role of postgraduate tutors is gradually weakening [9]. Because tutors spend more time in applying for projects, research projects, publishing papers, administrative positions or external part-time jobs, they make less time to guide graduate students, and do not play a role of supervision and guidance.

The graduate students lack the consciousness of innovation and the spirit of innovation [10]. Some graduate students are impetuous, unable to concentrate on academic research, indulge in social networking, and some graduate students still remain in their learning mindset. A few graduate students have poor scientific research ability and little knowledge of current research in this field.

The management system of the training unit is not perfect. The improvement of the quality of the academic master's postgraduate education depends on the improvement of the quality of the factors in the quality management system of the graduate education.

The problem of honesty and morality. There have some bad academic atmosphere in universities.

There is little difference in the process of training between academic postgraduates and professional degree postgraduates. In the course of training, the lack of teaching resources leads to the great similarity between the two training programs, which greatly affect the innovation of the academic postgraduates.

The Practice of Introducing ISO9000 into the Quality Management System of Education in the World. In 1990s, the ISO9000 was introduced into the education quality management system internationally $[11,12]$. The UK takes the lead in the use of ISO9000 to ensure the quality of teaching in Colleges and universities. By the end of 1998, 26 universities in the UK had established a quality management system in Colleges and universities in accordance with the ISO9000 standards. The United States has adopted ISO9000 standards in 220 institutions of higher learning (including Harvard, such as Harvard) in 1992. Theoretical research on the application of ISO9000 in the education industry is also widespread. Many countries have formulated the educational quality management standard. ISO has formulated ISO10015:1999 quality management training guidelines and ISO9001- education guidelines (2002). At present, ISO9000 series standard has been widely spread in the field of foreign education, many universities and secondary schools active promotion and application of quality management theory and method, in a series of ISO9000 standards for the establishment of teaching management system, improve the level of teaching management, and achieved remarkable results in hand to ensure the quality of education. Therefore, when the quality management system of ISO900 is applied to postgraduate teaching management and form an optimized structure, the quality of academic postgraduate education will be improved as a whole.

The Research Methods. The research flow chart of the ISO9000 quality management system for graduate students is shown in Figure 1.

The Practice of Postgraduate Management. The modern management mode, reflecting the overall optimization principle of the modern education thought, reflecting the suitability of stronger with society development, advanced management, advanced management objectives, accurate management, standardized management system, management link integrity, coordination, management environment, management the total and so on. We import in the management of the ISO9000 standard, is to play the greatest potential integration of system management, pursue the efficiency and quality of higher education from management: (1) Aiming at the quality problems in the training of graduate students academic mechanism, analysis of the quality assurance measures for the construction quality of the advantages and disadvantages. Provide realistic basis system. (2) Analysis of the academic quality of graduate education form, studied the factors affecting the quality, find out the important factors affecting the quality. (3) Using the methods of total quality management and ISO9000 quality management system, according to the actual situation of cultivating academic master graduate students in China, put forward construction of the academic graduate students in China internal quality assurance system of higher education. 


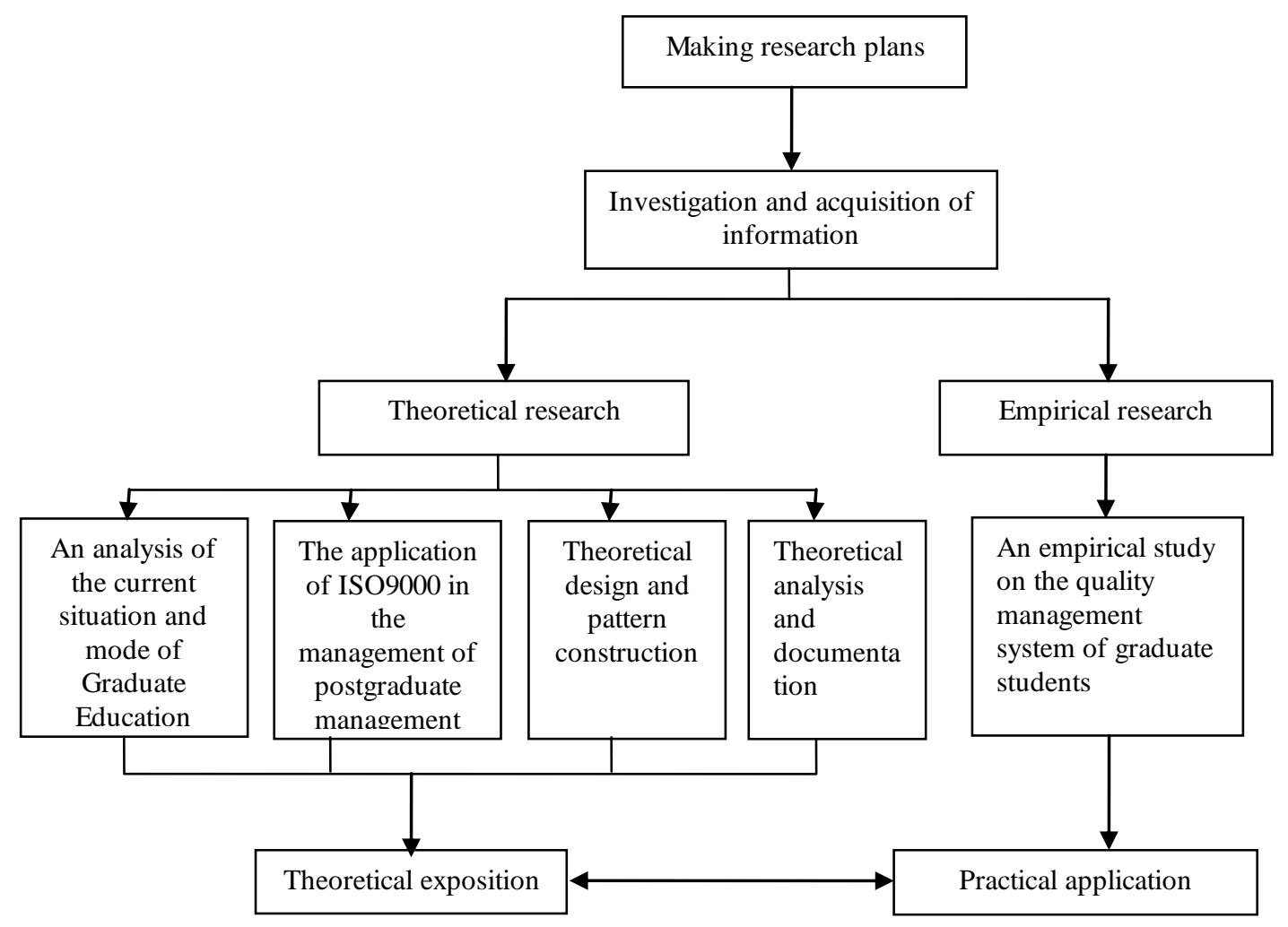

Figure 1. Flow chart of ISO9000 quality management system for Master graduate students

\section{Research Results}

The modern management mode, reflecting the overall optimization principle of the modern education thought, reflecting the suitability of stronger with society development, advanced management, advanced management objectives, accurate management, standardized management system, management link integrity, coordination, management environment, management the total and so on. The introduction of ISO9000 standard in management is to bring into play the maximum potential of the integrated system of management, and seek higher efficiency and quality of education from management. In the process of practice, has achieved the following results: (1) In order to explore the school quality management mode, promote the school personnel training objectives to better realize, realize the sustainable development of the school, the teaching idea from the "importance" and "process control". (2) The teaching management from the "open loop" to "closed loop" change. (3) As culturing with modern consciousness, a higher level of management, leadership team and teachers have strong research ability. (4) The research provided a reference sample for the management of postgraduate education and the pursuit of quality.

\section{The Practical Significance and Application Value}

The quality of education is the eternal pursuit of the school administrators, school management is always a topic worth exploring, close and comprehensive, permanent management mode and the quality of education and teaching of mutual dependency relation, so this study has practical significance to more extensive and more significant value. The adoption of international quality certification is the trend of the development of education management in twenty-first Century. The new mode of personnel training has been implemented in various disciplines and disciplines, and plays a certain role in achieving the goal of personnel training, optimizing teaching resources and improving the efficiency of running schools. The management program of academic master's degree has been communicated with the brotherhood 
colleges in the province. The experts from the Ministry of education came to our university to evaluate the postgraduate's teaching level. We affirmed our talent training mode. This study has the value of promoting and guiding the management of academic postgraduate students.

\section{Conclusion}

It is significant to introduce the ISO9000 quality management system into the postgraduate education management. The research group has experienced the nine year construction process of the quality system of the Institute of Oceanology of Yantai University, and is familiar with the operation and management of the quality system. According to the training objectives of academic postgraduates, and building good quality system based on good early work, we will further promote the management of graduate education in ordinary universities. Research closely combined with the talent demand of local dominant industries is in line with the general requirements of national education centered on the innovative talents needed by enterprises to cultivate economic construction, with obvious characteristics.

\section{Acknowledgments}

This research was supported by Shandong graduate student tutor guidance ability promotion project.

\section{References}

[1] I. Eardley, Y. Reisman, S. Goldstein et al. Existing and Future Educational Needs in Graduate and Postgraduate Education, The Journal of Sexual Medicine. 14 (2017) 475-485.

[2] M.E. Cowie, L.J. Nealis, S.B. Sherry et al. Perfectionism and academic difficulties in graduate students: Testing incremental prediction and gender moderation, Personality and Individual Differences. 123 (2018) 223-228.

[3] B. Kimarie, A.J. Pauline, N.M.P. Andrea. Academic-related stress among graduate students in nursing in a Jamaican school of nursing, Nurse Education in Practice. 20 (2016) 117-124.

[4] D.T. Coad. "That's My Face to the Whole Field!": Graduate Students' Professional Identity-Building through Twitter at a Writing Studies Conference, Computers and Composition. 45 (2017) 51-66.

[5] R.C. Zhang, H.M. Lai, P.W. Cheng et al. Longitudinal effect of a computer-based graduated prompting assessment on students' academic performance, Computers \& Education. 110 (2017) 181-194.

[6] E. Byl, K. Struyven, P. Meurs et al. The Value of Peer Learning for First-year Postgraduate University Students' Social and Academic Integration, Procedia - Social and Behavioral Sciences. 228 (2016) 299-304.

[7] S. Nallaya. An exploration of how first year students are inducted into their discipline's academic discourses, International Journal of Educational Research. 87 (2018) 57-66.

[8] R. Tzipora, B.T. Ayelet. To make a long story short: A rubric for assessing graduate students' academic and popular science writing skills, Assessing Writing. 32 (2017) 28-42.

[9] G. Swapnali, M.K. Lisa, C. Simon et al. A Systematic Review of Reciprocal Peer Tutoring within Tertiary Health Profession Educational Programs, Health Professions Education. 3 (2017) 64-78.

[10] B. Hendrickson. Intercultural connectors: Explaining the influence of extra-curricular activities and tutor programs on international student friendship network development, International Journal of Intercultural Relations. 63 (2018) 1-16.

[11] S. Daud, D. Abd. Wahab, R.S.M. Sidek et al.A Perception on the Effectiveness of Undergraduate and Graduate Programmes Management through an ISO Certification Scope Merger, Procedia Social and Behavioral Sciences. 1 (2011) 551-559.

[12] K. Ahmed, A. Akhondzada, J. Kurnitski et al. Occupancy schedules for energy simulation in new prEN16798-1 and ISO/FDIS 17772-1 standards, Sustainable Cities and Society. 35 (2017) 134-144. 